\title{
Effect of maternal low-dose glucose during Cesarean sectionon neonatal hypoglycemia
}

Saya Yoshizawa' ${ }^{1}$, Yoshihito Fujita ${ }^{1,2^{*}}$, Maiko Hoshika ${ }^{1}$, Nobuyoshi Kusama ${ }^{1}$ and Kazuya Sobue ${ }^{1}$

*Correspondence: fujita.yoshihito.823@mail.aichi-med-u.ac.jp

CrossMark

$\leftarrow$ Click for updates

\begin{abstract}
'Department of Anesthesiology and Intensive Care Medicine, Nagoya City University Graduate School of Medical Sciences, Nagoya, 467-8601, Japan.

2Department of Anesthesiology, Aichi Medical University School of Medicine, 1-1 Yazako Karimata, Nagakute, Aichi 480-1195, Japan.
\end{abstract}

\begin{abstract}
Background: Although rapid infusion of glucose during Cesarean section is associated with maternal and fetal hyperglycemia and subsequent neonatal reflex hypoglycemia, the optimal amount of glucose to administer is controversial. Therefore, we investigated whether intrapartum maternal low-dose $15 \mathrm{~g}$ glucose infusion during Cesarean section prevent neonatal hypoglycemia.

Methods: In this prospective controlled study, 60 patients were randomly assigned to two groups: $0 \%$ glucose (Group A) and 1\% glucose (Group B). Each group received $1500 \mathrm{ml}$ of the allocated solution before delivery. The primary outcome was the neonates' glucose concentrations 1 hour after birth and the secondary outcomes the neonates' glucose concentrations at 2 hours and their progress.

Results: After applying inclusion, 14 eligible patients were investigated. Umbilical venous and arterial blood glucose concentrations were significantly higher in Group B than in Group A (64.0 vs. 122.0 mg/dl and 64.0 vs. $118.5 \mathrm{mg} / \mathrm{dl}$ ); however, there were no significant differences in the neonates' glucose concentrations 1 and 2 hours after birth between Groups $\mathrm{A}$ and $\mathrm{B}(48.0$ vs. $51.0 \mathrm{mg} / \mathrm{dl}, \mathrm{P}=0.516 ; 56.0$ vs. $51.0 \mathrm{mg} / \mathrm{dl}, \mathrm{P}=$ 0.573 , respectively), and only one neonate $(10 \%)$ in Group A but six (50\%) in Group B developed transient tachypnea of the newborn requiring transfer to the NICU. The study was stopped after interim analysis.

Conclusions: Our study demonstrates that intrapartum maternal low-dose $15 \mathrm{~g}$ glucose infusion during Cesarean section does not prevent neonatal hypoglycemia more effectively than no maternal glucose infusion. Additionally, even such a small amount of glucose may be hazardous.
\end{abstract}

Keywords: Cesarean section, neonate, hypoglycemia, glucose, administration

\section{Introduction}

Hypoglycemia, one of the commonest metabolic problems in neonates, has been recognized for a century [1]. Neonatal hypoglycemia is associated with abnormalities on brain imaging and a range of developmental delays $[2,3]$. Neonates with hypoglycemia may exhibit diaphoresis, tachycardia, bradycardia, lethargy, coma, apnea, tachypnea, poor feeding, hypothermia, and seizures [1]. Because severe and prolonged hypoglycemia with clinical signs may result in neurologic injury, neonates with clinical signs require immediate intervention $[4,5]$. Absence of glucose administration during Cesarean section is reportedly associated with maternal and neonatal hypoglycemia [6]. How- ever, excessive glucose administration during Cesarean section has been claimed to induce maternal and fetal hyperglycemia and subsequent neonatal reflex hypoglycemia [7-9].

In light of this concern, several studies were conducted in the 1980s. Administration of more than $25 \mathrm{~g}$ glucose was found to induce neonatal hypoglycemia [7-9], whereas 7.5 g-glucose ${ }^{8}$ or 20 g-glucose [10] did not. However, in the cited studies, the mothers were subjected to overnight fasting preoperatively. A recently published evidence-based protocol for optimal perioperative care [11] specifies the duration of preoperative fasting should be 2 hours for liquids and $6-8$ hours for solids, even for patients undergoing elective Cesarean section [12]. Therefore,

(C) 2018 Yoshizawa et al; licensee Herbert Publications Ltd. This is an Open Access article distributed under the terms of Creative Commons Attribution License (http://creativecommons.org/licenses/by/3.0). This permits unrestricted use, distribution, and reproduction in any medium, provided the original work is properly cited. 
Yoshizawa et al. Journal of Anesthesiology \& Clinical Science 2018,

the data concerning glucose administration from the studies cited above may be invalid for mothers undergoing Cesarean section after adhering to current guidelines for fasting. Thus, the optimal dosage and speed of glucose infusion during Cesarean section have not been accurately established and there are no standard recommendations concerning glucose administration during Cesarean section $[12,13]$.

A recent study showed that umbilical cord blood glucose concentrations are lower after Cesarean section than after vaginal delivery [14] and that there may be a higher incidence of neonatal hypoglycemia in the former group. In addition, we would be concerned about hypoglycemia in neonates of mothers with low glucose concentrations because, in general, neonates' glucose concentrations are lower 1 hour after birth than at birth. Perioperative administration of adequate glucose is believed to prevent protein catabolism [15]. In addition, intravenous fluid preloading reduces the frequency of maternal hypotension after spinal anesthesia for Cesarean section; however, whether fluid preloading should include glucose is unclear [12]. Therefore, the purpose of this study was to determine whether intrapartum maternal low-dose glucose infusion during Cesarean section prevents neonatal hypoglycemia.

\section{Materials and methods}

\section{Preliminary study}

Prior to the main study, whether administration of low dose (15 g) glucose induces satisfactory glucose concentrations in umbilical blood without adverse effects was investigated. After the preliminary investigation protocol had been approved by our institutional ethics committee and registered at UMIN clinical trials (UMIN000005694) and written informed consent had been obtained from participants, the effects of administration of $15 \mathrm{~g}$ glucose during Cesarean section on the composition of umbilical artery blood were investigated. After enrollment, patients scheduled for Cesarean section were randomized to receive one of two different hydroxyethyl starch (HES) preparations administered intravenously over 40-50 minutes: one was a non-balanced 6\% HES, 70/0.45, C2/ C6 ratio 4:1 in isotonic saline with no glucose (sodium 154 $\mathrm{mg} / \mathrm{dl}$, chloride $154 \mathrm{mg} / \mathrm{dl}$ ) (Salinhes, Fresenius Kabi, Tokyo, Japan) and the other a balanced $6 \% \mathrm{HES}, 70 / 0.45, \mathrm{C} 2 / \mathrm{C} 6$ ratio 4:1 dissolved in Ringer's lactate with $1 \%$ glucose (sodium 105.6 $\mathrm{mg} / \mathrm{dl}$, chloride $92.3 \mathrm{mg} / \mathrm{dl}$, potassium $4.0 \mathrm{mg} / \mathrm{dl}$, calcium $2.7 \mathrm{mg} / \mathrm{dl}$, and lactate $20 \mathrm{mg} / \mathrm{dl}$ ) (Hespander, Fresenius Kabi, Tokyo, Japan).

The primary outcome of this preliminary study was differences in umbilical arterial glucose concentrations between the two groups and secondary outcomes were presence or absence of clinical evidence of hypoglycemia in the neonate and neonatal progress until discharge. Clinical evidence of hypoglycemia was defined as diaphoresis, tachycardia, bradycardia, lethargy, coma, apnea, tachypnea, hypothermia, and seizures. No serum glucose concentration for neonatal hypoglycemia was specified. An attending nurse could feed sugar water orally to neonates with evidence of hypoglycemia. If in this preliminary investigation showed satisfactory umbilical arterial glucose concentrations without adverse effects, we planned to investigate the effect on neonatal glucose concentrations. In general, after birth neonatal blood glucose concentrations decrease, reaching a trough level around 1 hour after birth, then increase, stabilizing around 2 hours after birth. We had sometimes encountered development of hypoglycemia after birth in neonates whose mothers had received standard anesthesia management and no intravenous glucose. We anticipated that administration of this small dose of glucose during Cesarean section would be associated with higher neonatal glucose concentrations than when no glucose had been administered to the mother. Therefore, we tried to confirm our hypothesis by measuring neonatal blood glucose concentrations 1 and 2 hours after birth.

\section{Main study}

The study was approved by the Institutional Ethics Committee of Nagoya City University (NCU-573, approved 8 October 2012), and registered at clinicaltrials.gov (NCT01706341). All the participants gave written informed consent for this prospective, randomized, controlled, single-blind study.

Inclusion criteria were as follows: American Society of Anesthesiologists physical status I and II women, singleton pregnancies, gestational age 36-42 weeks and planned for elective Cesarean section under spinal anesthesia. Exclusion criteria were weight $>75 \mathrm{~kg}$, height $>175 \mathrm{~cm}$, pregnancyinduced or chronic hypertension, gestational or pregestational diabetes, major systemic disease, fetal or placental abnormalities, multiple gestation, receiving ritodrine or other $\beta$-tocolytic agents, history of abnormal pregnancy (e.g., eclampsia or total placenta previa), or any contraindications to spinal anesthesia. Patients were randomly allocated by an envelope method into two groups: to receive acetated Ringer's solution containing no glucose (Group A) or acetated Ringer's solution containing $1 \%$ glucose (Group B). Each group received a $500 \mathrm{ml}$ preload of the allocated solution, administration of which solution was continued to a maximum of $1500 \mathrm{ml}$ by delivery. The maximum amount of glucose to be administered was set at $15 \mathrm{~g}$ and acetated Ringer's solution containing no glucose was administered after $1500 \mathrm{ml}$ of the allocated solution had been infused. All patients were scheduled to undergo elective Cesarean section in the afternoon and received no premedication. Food and clear fluid intake were allowed until 6 hours and 2 hours, respectively, before the operation.

\section{Anesthesia management}

On arrival in the operating room, standard monitoring, including electrocardiogram, noninvasive blood pressure (NIBP) and pulse oximetry, was instituted and an 18-gauge intravenous cannula was inserted and connected to the selected intravenous infusion, which was not commenced. Metoclopramide 10 
mg was administered intravenously. Maternal venous blood samples for measuring maternal blood glucose concentrations were obtained before starting the intravenous infusion and immediately after delivery. As soon as the preload had been completed, spinal anesthesia was induced with the patient in the right lateral position using $0.5 \%$ hyperbaric bupivacaine $12 \mathrm{mg}$ and fentanyl $10 \mu \mathrm{g}$ at the L3/4 level with a 25-gauge Quincke spinal needle. The patient was then immediately placed in a supine position with standard left lateral tilt, and oxygen $6 \mathrm{l} / \mathrm{min}$ routinely administered via a clear facemask. NIBP was continuously recorded until delivery, after which monitoring was continued at 5-minute intervals until the completion of surgery, this being a routine component of anesthetic care.

Maternal hypotension, defined as systolic $\mathrm{BP}<100 \mathrm{mmHg}$ or mean $\mathrm{BP}<60 \mathrm{mmHg}$, was treated with boluses of phenylephrine $0.1 \mathrm{mg}$; these were repeated if hypotension persisted or recurred. Atropine, $0.25 \mathrm{mg}$ intravenously, was administered for severe bradycardia. Block height after spinal anesthesia was measured by response to cold sensation using an ethanol alcohol pad every 5 min until a stable block height had been achieved; surgical incision was allowed when T6 sensory blockade had been established.

\section{Sampling}

The study period began when the patient started receiving her preload and finished on completion of skin closure. The induction-delivery, skin incision-delivery, uterine incision-delivery intervals and duration of surgery were recorded. Infusion of the selected solution was discontinued following delivery of the fetus in all participants. Total volume and duration of solution infusion and total dose of glucose were recorded. Total number of phenylephrine and atropine boluses required and episodes of nausea and/or vomiting until delivery were recorded in both groups. Apgar scores were assessed at 1 and 5 minutes by a pediatrician blinded to group assignment. Neonatal weight and umbilical venous and arterial blood gases obtained from a double-clamped segment of the umbilical cord were also documented. Neonatal blood samples were also obtained 1 and 2 hours after birth by heel stick.

\section{Measurement of serum parameters}

Maternal blood glucose concentrations prior to intravenous infusion and umbilical cord blood glucose concentrations, $\mathrm{pH}$, $\mathrm{PO} 2, \mathrm{PCO} 2$, and base excess, lactate, and electrolytes were analyzed using a gas analyzer (ABL800FEX, Radiometer, Tokyo, Japan) gas analyzer. Maternal blood was obtained on delivery and neonatal blood 1 and 2 hours after delivery by heel stick and glucose concentrations analyzed using self-monitoring blood glucose meters (Medisafe Fit, Terumo, Tokyo, Japan).

\section{Outcomes}

No blood glucose concentration was defined for neonatal hypoglycemia. As in the preliminary study, a nurse could feed sugar water orally to a neonate with clinical evidence of hypoglycemia. The primary outcome was difference between the two groups in neonatal blood glucose 1 hour after birth and secondary outcomes were blood glucose 2 hours after birth, presence or absence of evidence of neonatal hypoglycemia, and neonatal progress.

\section{Statistical analysis}

Statistical analyses were performed with the computerized program Statistical Package for the Social Sciences (SPSS 19.0, Chicago IL, USA). Normality was assessed by the Shapiro-Wilk test for continuous variables. Data are presented as the mean \pm standard deviation if normally distributed and data as median (interquartile range) if not normally distributed. Differences between the two groups in means were analyzed with Student's t-test if distribution was normal and with Mann-Whitney $U$ test. The $X 2$ and Fisher's exact tests were used to compare categorical data of the two groups. All $P$ values were two-tailed. $P$ values less than 0.05 were considered statistically significant.

A computer program (IBM SPSS Sample Power 3, Chicago IL, USA) was used to calculate the required sample size for the primary endpoint: determination of the difference in 1-hour neonatal glucose concentrations between maternal infusions containing $15 \mathrm{~g}$ glucose versus no glucose. In the preliminary study umbilical artery blood glucose concentrations were 97.0 $\mathrm{mg} / \mathrm{dl}$ with $15 \mathrm{~g}$ glucose and $56.5 \mathrm{mg} / \mathrm{dl}$ without glucose. We considered $10-15 \mathrm{mg} / \mathrm{dl} 1$ hour after birth to be a clinically significant difference in neonatal glucose concentration and used these preliminary data to estimate the required sample size. The effect size $(E)$ in glucose concentration in umbilical artery blood was the difference between the means of each group, that is, $97-56=41 \mathrm{mg} / \mathrm{dl}$. In general, the standard deviation of the alteration is smaller than that of the original variable; $14.0 \mathrm{mg} / \mathrm{dl}$, the standard deviation of umbilical artery blood glucose concentrations with $15 \mathrm{~g}$ glucose, was therefore used as the standard deviation of the outcome's alteration (S). It was assumed that the difference between means in the two groups' blood glucose concentrations 1 hour after birth would be unchanged or one third smaller than 41 $\mathrm{mg} / \mathrm{dl}$; that is, $13-41 \mathrm{mg} / \mathrm{dl}$ would be a clinically significant difference. Standardized effect size (E/S) was therefore (13 $41) / 14 ; 0.93-2.93$. A total of 5-23 patients in each group was thus required to detect a clinically significant difference between means, assuming a two-tailed type I error of $5 \%$ and type II error of $10 \%$. We therefore aimed to enroll 30 patients in each group.

\section{Results \\ Preliminary study}

Relevant maternal and neonatal characteristics and umbilical arterial values at birth in the preliminary study are summarized in Table 1. We found that administration of $15 \mathrm{~g}$ glucose to the mother induced higher glucose concentrations in umbilical 
Yoshizawa et al. Journal of Anesthesiology \& Clinical Science 2018,

http://www.hoajonline.com/journals/pdf/2049-9752-7-2.pdf

Table 1. Maternal and neonatal physical characteristics and umbilical arterial blood values at birth in the preliminary study.

\begin{tabular}{|c|c|c|c|}
\hline & $\begin{array}{l}\text { Non-balanced } \\
\text { HES }\end{array}$ & Balanced HES & $P$-value \\
\hline & $(\mathrm{n}=8)$ & $\mathrm{n}=(11)$ & \\
\hline Maternal Age (year) & $36.5(31.0,42.0)$ & $32.0(28.5,35.5)$ & 0.22 \\
\hline Maternal Height $(\mathrm{cm})$ & $159.0(154.8,163.5)$ & $\begin{array}{l}158.0(155.5, \\
159.5)\end{array}$ & 0.48 \\
\hline Maternal Weight (kg) & $67.0(61.7,74.5)$ & $61.6(55.1,63.85)$ & 0.091 \\
\hline $\begin{array}{l}\text { Incision-delivery } \\
\text { interval (min) }\end{array}$ & $3.0(2.0,3.3)$ & $1.0(1.0,2.0)$ & 0.076 \\
\hline 1 min Apgar score & $9.0(8.0,9.0)$ & $8.0(8.0,9.0)$ & 0.245 \\
\hline 5 min Apgar score & $10.0(9.0,10.0)$ & $9.0(9.0,9.5)$ & 0.101 \\
\hline Infant weight (kg) & $2961(2742,3281)$ & $2882(2698,3298)$ & 0.563 \\
\hline \multicolumn{4}{|c|}{ Umbilical arterial values at birth } \\
\hline $\mathrm{pH}$ & $7.287(7.250,7.304)$ & $\begin{array}{l}7.314(7.262, \\
7.330)\end{array}$ & 0.591 \\
\hline PCO2 (mmHg) & $55.5(46.0,57.6)$ & $47.1(44.8,55.0)$ & 0.342 \\
\hline $\mathrm{PO} 2(\mathrm{mmHg})$ & $18.4(16.4,20.5)$ & $21.8(18.8,28.25)$ & 0.177 \\
\hline $\mathrm{Na}(\mathrm{mmol} / \mathrm{L})$ & $135.0(134.0,135.0)$ & $\begin{array}{l}132.0(128.5, \\
133.0)\end{array}$ & $0.040^{*}$ \\
\hline $\mathrm{K}(\mathrm{mmol} / \mathrm{L})$ & $4.75(4.18,5.23)$ & $4.40(4.00,4.75)$ & 0.281 \\
\hline $\mathrm{Cl}(\mathrm{mmol} / \mathrm{L})$ & $109.5(108.8,111.0)$ & $\begin{array}{l}107.0(105.5, \\
108.5)\end{array}$ & $0.0196^{*}$ \\
\hline $\mathrm{Ca}(\mathrm{mmol} / \mathrm{L})$ & $1.43(1.36,1.45)$ & $1.40(1.38,1.44)$ & 0.967 \\
\hline $\mathrm{Lac}(\mathrm{mg} / \mathrm{dl})$ & $21.5(19.3,25.0)$ & $24.0(20.0,28.5)$ & 0.590 \\
\hline $\mathrm{Hb}(\mathrm{g} / \mathrm{dl})$ & $14.4(13.8,15.1)$ & $14.8(13.8,15.4)$ & 0.591 \\
\hline $\mathrm{BE}(\mathrm{mmol} / \mathrm{L})$ & $-2.15(-3.40,-1.50)$ & $-3.70(-4.10,-1.90)$ & 0.535 \\
\hline Glu (mg/dl) & $56.5(52.5,61.3)$ & $97.0(94.5,102.5)$ & $0.000326^{\star}$ \\
\hline
\end{tabular}

Values are expressed as median (25\%, 75\% percentile).

HES, hydroxyethyl starch; Lac, lactate;BE, base excess.

A balanced HES includes $1 \%$ glucose.

P-values obtained using Mann-Whitney U test.

Difference in $\mathrm{Na}$ and $\mathrm{Cl}$ is statistically significant; however, this small difference is not clinically meaningful.

${ }^{\star} \mathrm{P}<0.05$ (significant).

artery blood than no glucose $(97.0 \mathrm{mg} / \mathrm{dl} ; 55.6 \mathrm{mg} / \mathrm{dl}$ without glucose) and had no adverse effects on neonatal progress up till discharge.

\section{Main study}

From December 2012 through July 2013, 22 women met the inclusion criteria and were enrolled in the main study and randomized (Figure 1). We excluded eight of these patients after randomization. One patient from Group A (no glucose) was excluded because she required an epidural block, spinal block having achieved insufficient anesthesia. Another patient from Group A and six patients from Group B ( $1 \%$ glucose) were excluded because they required admission to the neonatal intensive care unit (NICU) for transient tachypnea of the newborn and five infants in Group B required intubation. Therefore, Group A comprised eight patients and Group B six.

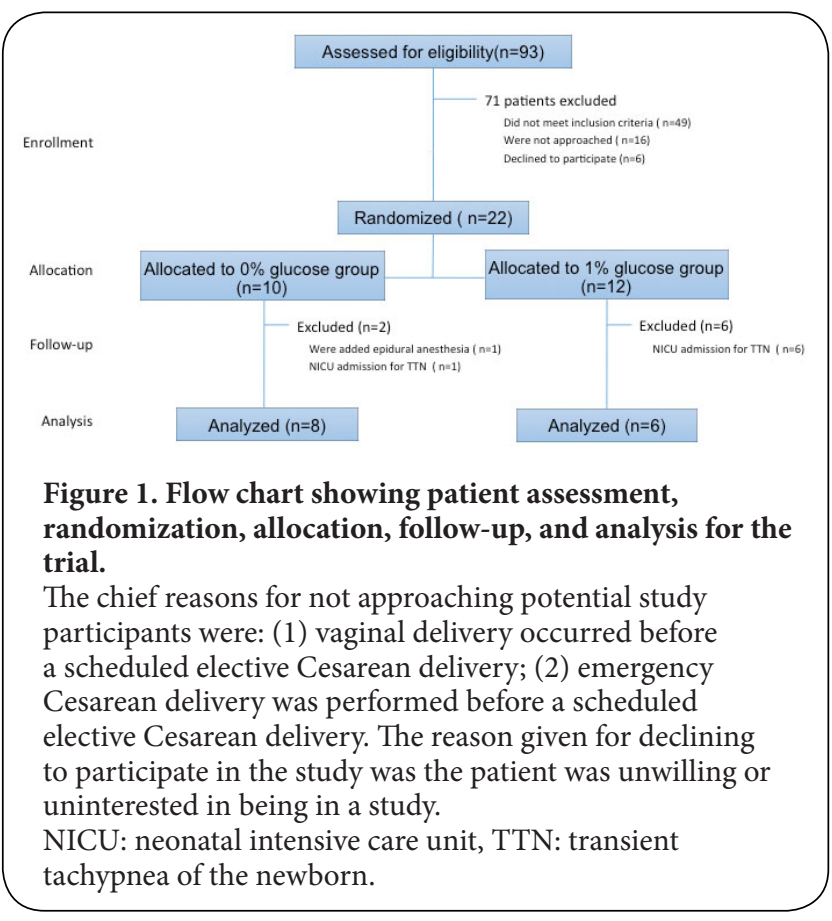

The only difference in maternal and neonatal characteristics between groups was gestational age (Table 2). There were no significant differences in time-intervals, volume of intravenous fluids infused at birth, incidence of hypotension, bradycardia, nausea and/or vomiting, or total dose of phenylephrine between the groups; however, total glucose infused at delivery did differ (Table 3). There were no significant differences in either umbilical vein or umbilical artery blood $\mathrm{pH}, \mathrm{PO} 2, \mathrm{PCO}$, $\mathrm{BE}$, lactate or electrolytes (Table 3). One neonate in Group B had fetal acidosis, as defined by $\mathrm{pH}<7.2$, but Apgar scores were 7 or greater at 1 and 5 minutes of age.

Maternal blood glucose concentrations just before starting the intravenous infusion were similar in the two groups (72.0 vs. $68.5 \mathrm{mg} / \mathrm{dl} ; \mathrm{P}=0.846$ ) (Table 4). At delivery, maternal blood glucose concentrations differed significantly between the groups (64.0vs. $122 \mathrm{mg} / \mathrm{dl} ; \mathrm{P}=0.00239$ ). Umbilical vein and artery blood glucose concentrations after delivery were significantly higher in Group B than in Group A (64.0 vs. 118.5 $\mathrm{mg} / \mathrm{dl}, \mathrm{P}=0.00066 ; 49.5 \mathrm{vs} .89 .5 \mathrm{mg} / \mathrm{dl}$, respectively, $\mathrm{P}=0.00231$ ). However, glucose concentrations, which were higher in the cord blood of Group B than Group A patients at birth, did not differ significantly 1 and 2 hours after birth (48.0 (40.8, $53.0)$ vs. $51.5(48.5,55.3) \mathrm{mg} / \mathrm{dl}, \mathrm{P}=0.516 ; 56.0(50,61.3)$ vs. 51 $(49.3,55) \mathrm{mg} / \mathrm{dl}, \mathrm{P}=0.573$, respectively). Glucose concentrations tended to be lower at 1 hour in group $A$ but at 2 hours in Group B; however, glucose concentrations were not stable in either group, ranging from 37 to $56 \mathrm{mg} / \mathrm{dl}$ at 1 hour and from 42 to $69 \mathrm{mg} / \mathrm{dl}$ at 2 hours in Group A and from 35 to $78 \mathrm{mg} / \mathrm{dl}$ at 1 hour and 31 to $73 \mathrm{mg} / \mathrm{dl}$ at 2 hours in Group B. Seven neonates had glucose concentrations $<50 \mathrm{mg} / \mathrm{dl}$; however, no neonates had clinical evidence of hypoglycemia 
Yoshizawa et al. Journal of Anesthesiology \& Clinical Science 2018, http://www.hoajonline.com/journals/pdf/2049-9752-7-2.pdf

Table 2. Maternal and infant physical characteristics of participants in the main study.

\begin{tabular}{|c|c|c|c|}
\hline & Group A & Group B & $P$-value \\
\hline & $(\mathrm{n}=8)$ & $(n=6)$ & \\
\hline Maternal Age (year) & $37.5(35.8,40.5)$ & $36.0(33.8,36.0)$ & 0.102 \\
\hline Maternal Height $(\mathrm{cm})$ & $156(154.5,157.8)$ & $155.8(155.8,159.5)$ & 0.603 \\
\hline Maternal Weight (kg) & $62.3(58.8,63.9)$ & $61.3(59.4,62.8)$ & 0.746 \\
\hline BMI & $25.3(24.6,26.1)$ & $24.4(22.8,25.7)$ & 0.573 \\
\hline Gestational age (weeks) & $37(37,37.3)$ & $38(38,38)$ & $0.0447^{\star}$ \\
\hline Previous cesarean delivery / breech presentation (n) & $7 / 1$ & $4 / 2$ & 0.538 \\
\hline 1 min Apgar score & $8(8,8)$ & $8(8,8)$ & 0.47 \\
\hline 5 min Apgar score & $9(9,9)$ & $9(9,9)$ & 1 \\
\hline Infant weight (g) & $2893(2655,3020)$ & $2855(2772,3108)$ & 0.755 \\
\hline Fetal acidosis (umbilical arterial $\mathrm{PH}<7.2$ ) & 1 & 0 & 1 \\
\hline
\end{tabular}

Values are expressed as median (25\%, $75 \%$ percentile).

P-value obtained using Mann-Whitney U tests or Fisher's exact tests.

Difference in gestational age is statistically significant; however, this small difference is not clinically meaningful.

${ }^{\star} \mathrm{P}<0.05$ (significant).

Table 3. Obstetric and anesthetic data and umbilical vein and artery blood glucose concentrations at birth.

\begin{tabular}{llll}
\hline & Group A & Group B & P-value \\
\hline & $(\mathbf{n}=\mathbf{8})$ & $(\mathbf{n}=\mathbf{6})$ & \\
Spinal anesthesia-delivery time (min) & $23.5(21.0,24.8)$ & $23.5(23.0,24.8)$ & 0.647 \\
Uterine incision-delivery time (min) & $2.0(1.0,2.0)$ & $1.0(1.0,1.8)$ & 0.437 \\
Incidence of hypotension (n) & 7 & 6 & 1 \\
Total dose of phenylephrine (mg) & $0.55(0.28,0.90)$ & $0.50(0.28,0.65)$ & 0.558 \\
Incidence of bradycardia (n) & 0 & 1 & 0.429 \\
Incidence of nausea and/or vomiting & 1 & 0 & 1 \\
Total IV fluids at delivery (ml) & $1500(1475,1600)$ & $1500(1500,1575)$ & 0.734 \\
Total glucose infusion at delivery (g) & 0 & $15.0(15.0,15.0)$ & $0.00055^{*}$ \\
\hline Umbilical vein at birth & & & \\
\hline pH & $7.35(7.31,7.37)$ & $7.38(7.37,7.39)$ & 0.228 \\
PCO2 (mmHg) & $42.3(34.6,50.7)$ & $40.2(37.4,43.0)$ & 0.852 \\
PO2 (mmHg) & $25.8(16.8,31.7)$ & $33.4(32.1,37.2)$ & 0.093 \\
Lac (mg/dl) & $12.0(10.8,21.5)$ & $15.0(14.3,16.5)$ & 0.332 \\
BE (mmol/L) & $-3.1(-5.1,-1.6)$ & $-1.5(-2.9,-0.3)$ & 0.228 \\
Umbilical artery at birth & & & \\
pH & $7.33(7.31,7.35)$ & $7.32(7.31,7.33)$ & 0.755 \\
PCO2 (mmHg) & $47.4(44.9,51.9)$ & $51.3(47.1,53.8)$ & 0.475 \\
PO2 (mmHg) & $18.0(16.1,22.5)$ & $18.8(15.5,19.9)$ & 0.491 \\
Lac (mg/dl) & $15.5(14.0,24.0)$ & $20.5(17.0,21.8)$ & 0.824 \\
BE (mmol/L) & $-2.4(-3.6,-0.30)$ & $-0.90(-1.70,0.13)$ & 0.22 \\
\hline Val a & & & \\
\hline
\end{tabular}

Values are expressed as median $(25 \%, 75 \%$ percentile). IV, intravenous; Lac, lactate; BE, base excess.

The only variable to differ significantly between groups is amount of glucose infused. ${ }^{*} \mathrm{P}<0.05$ (significant). 
Yoshizawa et al. Journal of Anesthesiology \& Clinical Science 2018,

Table 4. Serum glucose concentrations in maternal blood before fluid infusion and at delivery, umbilical vein and artery.

\begin{tabular}{llll}
\hline & $\begin{array}{l}\text { Group A } \\
(\mathbf{n = 8})\end{array}$ & $\begin{array}{l}\text { Group B } \\
(\mathbf{n = 6})\end{array}$ & P-value \\
\hline Maternal glucose before intravenous infusion & $72.0(70.8,73.5)$ & $68.5(66.5,76.5)$ & 0.846 \\
Maternal glucose at delivery & $64.0(62.366 .5)$ & $122(114.5,125.8)$ & $0.00239^{*}$ \\
Umbilical venous glucose & $64.0(58.8,69.3)$ & $118.5(110.5,124.3)$ & $0.00066^{*}$ \\
Umbilical arterial glucose & $49.5(44.0,53.5)$ & $85.0(82.5,86.8)$ & $0.00231^{*}$ \\
Neonatal glucose at 1 hour & $48.0(40.8,53.0)$ & $51.5(48.5,55.3)$ & 0.516 \\
Neonatal glucose at 2 hour & $56.0(50.0,61.3)$ & $51.0(49.3,55.0)$ & 0.573 \\
\hline
\end{tabular}

and the hospital courses of the neonates until discharge were unremarkable.

We stopped this study based on results of interim analysis for the following two reasons. First, only one neonate in Group A but six in Group B developed transient tachypnea of the newborn requiring transfer to the NICU (Figure 1); this complication had not occurred in the preliminary study. Although the number of affected few neonates was small (1/10 vs. $6 / 12$; Fisher's exact test, $\mathrm{P}=0.156$ ), we could not overlook this morbidity given that our focus was on maternal and neonatal safety. With a $P$ value of 0.156 , we had to suspect our study was unsafe. Second, we did not consider the difference in neonatal glucose concentrations between the two groups to be clinically significant. At this point, the mean neonatal glucose concentration 1 hour after birth was only a little higher with maternal glucose administration than that without glucose administration $(51.5(48.5,55.3) \mathrm{mg} / \mathrm{dl}$ with maternal glucose versus $48.0(40.8,53.0) \mathrm{mg} / \mathrm{dl}$ without maternal glucose). We therefore recalculated the required sample size using these interim data and found that a total sample size of 90 patients in each group was required to detect a $6 \mathrm{mg} / \mathrm{dl}$ difference in the mean, assuming a two-tailed type I error of $5 \%$ and type II error of $10 \%$. Thus, we had to enroll about 100 patients in each group, if possible. We initially considered that a difference of $>10 \mathrm{mg} / \mathrm{dl}$ was clinically significant. Additionally, 2 hours after birth, the relationship between neonatal blood glucose and maternal glucose infused reversed; the neonatal glucose concentration was lower with maternal glucose administration than without glucose $(51(49.3,55) \mathrm{mg} / \mathrm{l}$ vs. 56.0 $(50,61.3) \mathrm{mg} / \mathrm{dl}$, respectively). We considered these findings sufficient grounds to stop the study.

\section{Discussion}

Our study demonstrates that intrapartum maternal low-dose glucose $(15 \mathrm{~g})$ does not prevent neonatal hypoglycemia. There is a little difference in neonatal blood glucose between maternal low-glucose group and no glucose group. Additionally, more neonates in maternal low-glucose group developed transient tachypnea of the newborn requiring transfer to the NICU than those in no glucose group.Thus, caution about administering even only $15 \mathrm{~g}$ glucose to patients undergoing Cesarean section is necessary.

There are several possible explanations for the failure of a small intrapartum maternal glucose infusion to prevent neonatal hypoglycemia andmore neonates developing transient tachypnea in this group. First, the 15 g glucose we selected for this study may have been excessive for our patients, who were all Japanese and, unsurprisingly, smaller (mean body weight; $61.4 \pm 6.9 \mathrm{~kg}$ ) than the European and US-American participants in previous studies. Second, a glucose infusion rate of $20 \mathrm{~g} /$ hour may excessive for our patients. In a previous study, a glucose infusion rate of more than $20 \mathrm{~g} /$ hour was found to be excessive [16]. In our protocol, the glucose infusion rate was almost equal to $20 \mathrm{~g}$ /hour because of $15 \mathrm{~g}$ glucose was infused within 45 minutes. We showed changes in glucose concentration from baseline (maternal glucose, umbilical cord on delivery, 1-hour neonate, and 2-hour neonate) in Figure 2. Although the number was small, in glucose group there was significant difference of glucose among umbilical artery on delivery, 1-hour neonate and 2-hour neonate $(\mathrm{P}=0.0094$,

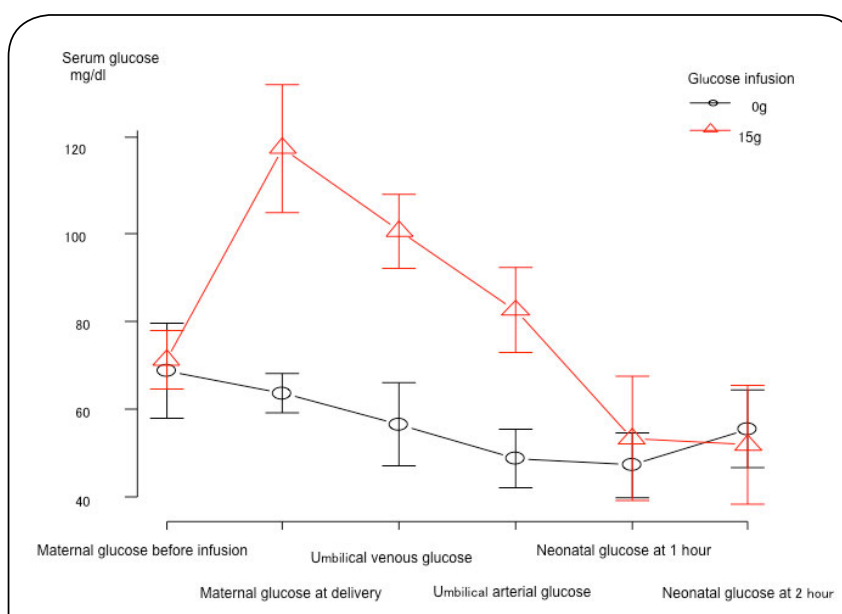

Figure 2. Changes in glucose concentrations from baseline. In glucose group rapid change of glucose was demonstrated. On the other hand, in no glucose group gradual change was indicated. 
Friedman test), however, in no glucose group there was no difference of glucose among them ( $P=0.0531$, Friedman test). We thought that this rapid change of glucose might induce respiratory complication. Rapid infusion of a large amount of glucose during Cesarean section is associated with maternal and fetal hyperglycemia, hyperinsulinemia, and neonatal hypoglycemia.

Previous studies have reported that maternal blood glucose concentrations at delivery of more than $120-150 \mathrm{mg} / \mathrm{dl}[6-8,10,16]$ are associated with adverse effects and our Group B patients' mean value of $122(114.5,125.5) \mathrm{mg} / \mathrm{dl}$ is almost equal to these high-risk concentrations. These data suggest that our low-dose glucose administration may have been capable of inducing maternal blood glucose concentrations to be high enough to induce neonatal hypoglycemia. On the other hand, in our data the maternal glucose concentrations without glucose at neonatal birth was $64.0(62.3,66.5) \mathrm{mg} / \mathrm{dl}$, which was relatively low, no-glucose administration might be insufficient for our patients and a little hypoglycemic state of mother made the neonate hypoglycemia. We allowed all patients food and clear fluid until 6 hours and 2 hours ago, according to recommendation from the United States, the same as that for general surgery, but all our patients had no sugar clear fluid. Because the calorie consumption for a pregnant woman is higher than a not-pregnant woman, we have to pay more attention to hypoglycemia.

The definition of neonatal hypoglycemia is controversial because transient and asymptomatic hypoglycemia often occurs in the first few hours after birth. Most neonates compensate for a transitional low blood glucose with endogenous fuel production through gluconeogenesis, glycogenolysis, and ketogenesis [17-19]. The umbilical venous plasma glucose concentration at birth is $60 \%$ to $80 \%$ that of the maternal venous glucose concentration. Although plasma glucose concentrations decline by $20-30 \mathrm{mg} / \mathrm{dL}$ in healthy neonates during the first 2 hours of postnatal life, the decline is transient and asymptomatic. The present findings may reflect the ability of neonates to adapt to changes in glucose concentrations and the limited ability of interventions to change these concentrations. Glucose metabolism differs between normal neonates and neonates at significant risk of hypoglycemia, and there is a lack of significant correlations between plasma glucose concentration, clinical signs, and long-term sequelae. A meta-analysis of studies published from 1986 to 1994 investigated thresholds for low plasma glucose concentrations in term healthy newborns who were mostly mixed fed (breastfed and formula-fed) or formula-fed [20]. These authors recommended adoption of the following thresholds for low plasma glucose concentrations in full-term normal newborns: 28,40 , and $48 \mathrm{mg} / \mathrm{dL}$ at 1 to 2,3 to 47 , and 48 to 72 hours of life. The Academy of Breastfeeding Medicine (ABM) and American Association of Pediatrics (AAP) have published guidelines for blood glucose monitoring and treatment of hypoglycemia in neonates [21]. Both suggest that routine screening and monitoring of blood glucose concentrations is not needed in healthy term newborn infants after entirely normal pregnancies and deliveries and that glucose screening should be performed only on at-risk infants and those with clinical signs compatible with hypoglycemia $[22,23]$.

The AAP guidelines also recommend thresholds for plasma glucose concentration for diagnosing neonatal hypoglycemia in at-risk late-preterm and term infants. Further investigation and immediate intravenous glucose treatment should be instituted in infants with clinical signs and plasma glucose concentrations of less than $40 \mathrm{mg} / \mathrm{dl}$. In the case of at-risk but asymptomatic term formula-fed infants, they recommended feeding within 1 hour and screening blood glucose concentration 30 minutes after the first feed. If glucose concentrations decrease to less than $25 \mathrm{mg} / \mathrm{dl}$ (birth to 4 hours of age) or 35 $\mathrm{mg} / \mathrm{dl}$ (4-24 hours of age), they suggest feeding and checking in 1 hour. If the glucose concentrations have not changed, they recommend intravenous glucose. Our study included only no-risk full-term infants; however, a few neonates had blood glucose concentrations of $30 \mathrm{mg} / \mathrm{dl}$. None had any clinical evidence of hypoglycemia and none had complications.

Few studies have evaluated long-term outcomes of neonatal hypoglycemia. McKinlay et al. [23] reported a prospective study of neonatal hypoglycemia in babies who were late preterm or term ( $\geq 35$ weeks' gestation) and at risk of hypoglycemia.

Their protocol involved intensive glucose monitoring and treatment aimed at maintaining plasma glucose concentrations above $47 \mathrm{mg} / \mathrm{dl}$ during the first 48 hours after birth. The investigators concluded that there was no association between hypoglycemia during the first 48 hours and neurodevelopmental outcome at age 2 years [23]. Goode et al. [24] have also reported finding no significant differences in cognitive or academic skills between preterm infants with and without hypoglycemia at 3,8, and 18 years of age. They defined the cutoff for hypoglycemia cutoffs as glucose concentration less than $45 \mathrm{mg} / \mathrm{dl}$ [24]. In contrast, Kaiser et al. [25] reported an association between early (within the first 3 hours of life) transient newborn hypoglycemia and lower literacy and mathematics achievement test scores at age 10 years. This study was a retrospective, population-based cohort study of 1395 term and preterm (23-42 weeks' gestation) infants. These authors defined varying degrees of hypoglycemia, namely glucose concentrations of less than 35,40 , and $45 \mathrm{mg} / \mathrm{dl}$; newborns received intravenous dextrose or early feeding when their blood glucose concentrations were less than $35 \mathrm{mg} / \mathrm{dl}$. All degrees of early transient hypoglycemia were significantly associated with decreased literacy and mathematics achievement test results. The findings vary, indicating the need to further evaluate long-term outcomes of neonatal hypoglycemia.

Our study had several limitations. First, the results of our interim analysis prompted us to stop the study. In our main study, the incidence of neonatal respiratory failure and requirement for intubation was greater in Group B (maternal 
glucose administered), whereas in the preliminary study, these complications did not occur. We could identify no explanation for this difference other than the small dose of glucose administered because the groups did not differ in other relevant variables such as the patient- and anesthesiarelated variables of maternal systolic blood pressure $>100$ $\mathrm{mmHg}$, incision-delivery time (mean 1.5 minutes). There were too few cases and these adverse events may have occurred incidentally. Second, the measurement instrument was not the one device. We used a Medisafe Fit meter (Terumo, Tokyo, Japan) to measure both neonate's glucose concentrations and the mothers' glucose concentrations at delivery by heel prick. This instrument meets the standards of ISO 15197 and ensures less than $\pm 8 \mathrm{mg} / \mathrm{dl}$ at $24 \mathrm{mg} / \mathrm{dl}$ and $40 \mathrm{mg} / \mathrm{dl}$ according to their own data. This may not have been sufficiently precise.

\section{Conclusion}

Our study demonstrated that intrapartum maternal low-dose glucose infusion $(15 \mathrm{~g})$ during Cesarean section does not prevent neonatal hypoglycemia more effectively than no maternal glucose infusion. Indeed, administering even such a small amount of glucose to patients undergoing Cesarean section may be hazardous.

\section{Competing interests}

The authors declare that they have no competing interests.

\section{Authors' contributions}

\begin{tabular}{|l|c|c|c|c|c|}
\hline Authors' contributions & SY & YF & MH & NK & KS \\
\hline Research concept and design & $\checkmark$ & $\checkmark$ & $\checkmark$ & $\checkmark$ & $\checkmark$ \\
\hline Collection and/or assembly of data & $\checkmark$ & $\checkmark$ & $\checkmark$ & $\checkmark$ & -- \\
\hline Data analysis and interpretation & $\checkmark$ & $\checkmark$ & $\checkmark$ & $\checkmark$ & -- \\
\hline Writing the article & $\checkmark$ & $\checkmark$ & -- & -- & -- \\
\hline Critical revision of the article & $\checkmark$ & $\checkmark$ & -- & -- & -- \\
\hline Final approval of article & -- & $\checkmark$ & -- & -- & $\checkmark$ \\
\hline Statistical analysis & $\checkmark$ & $\checkmark$ & -- & -- & -- \\
\hline
\end{tabular}

\section{Acknowledgement}

We thanked Dr. Megumi Harima, Dr. Kazuma Fujikake, Dr. Naoko Takeuchi, Dr. Min-Hye So, Dr. Shinichiro Yoshimura, Dr. Yoshiki Sento, Dr. Satoshi Aoki, Dr. Yukiko Mori, Dr. Taiki Kojima, Dr. Kentaro Miyake, and Dr. Haruko Ota for helping to collect atrial samples and acquire data.

\section{Publication history}

EIC: D. John Doyle, Case Western Reserve University, USA.

Received: 11-Mar-2018 Final Revised: 13-April-2018

Accepted: 17-April-2018 Published: 03-May-2018

\section{References}

1. Cornblath M, Nakamura H, Zetterstrom R and Kobayashi N. An international symposium on neonatal hypoglycemia: thirty years later. Does it injure the neonatal brain? Acta Paediatr Jpn. 1997; 39 Suppl 1:S1-6. | PubMed

2. Tin W, Brunskill G, Kelly T and Fritz S. 15-year follow-up of recurrent "hypoglycemia" in preterm infants. Pediatrics. 2012; 130:e1497-503. | Article I PubMed
3. Burns CM, Rutherford MA, Boardman JP and Cowan FM. Patterns of cerebral injury and neurodevelopmental outcomes after symptomatic neonatal hypoglycemia. Pediatrics. 2008; 122:65-74. | Article | PubMed

4. Cornblath $M$ and Ichord R. Hypoglycemia in the neonate. Semin Perinatol. 2000; 24:136-49. | Article | PubMed

5. Boluyt $N$, van Kempen A and Offringa M. Neurodevelopment after neonatal hypoglycemia: a systematic review and design of an optimal future study. Pediatrics. 2006; 117:2231-43. I Article I PubMed

6. Fukuda I, Matsuda H, Sugahara S and Kazama T. The effect of intravenous glucose solutions on neonatal blood glucose levels after cesarean delivery. J Anesth. 2013; 27:180-5. | Article | PubMed Abstract | PubMed FullText

7. Kenepp NB, Kumar S, Shelley WC, Stanley CA, Gabbe SG and Gutsche $\mathrm{BB}$. Fetal and neonatal hazards of maternal hydration with $\mathbf{5 \%}$ dextrose before caesarean section. Lancet. 1982; 1:1150-2. I Article I PubMed

8. Grylack LJ, Chu SS and Scanlon JW. Use of intravenous fluids before cesarean section: effects on perinatal glucose, insulin, and sodium homeostasis. Obstet Gynecol. 1984; 63:654-8. | PubMed

9. Philipson EH, Kalhan SC, Riha MM and Pimentel R. Effects of maternal glucose infusion on fetal acid-base status in human pregnancy. Am J Obstet Gynecol. 1987; 157:866-73. | Article | PubMed

10. Ramanathan S, Masih AK, Ashok U, Arismendy J and Turndorf H. Concentrations of lactate and pyruvate in maternal and neonatal blood with different intravenous fluids used for prehydration before epidural anesthesia. Anesth Analg. 1984; 63:69-74. | Article I PubMed

11. Lassen K, Soop M, Nygren J, Cox PB, Hendry PO, Spies C, von Meyenfeldt MF, Fearon KC, Revhaug A, Norderval S, Ljungqvist O, Lobo DN and Dejong $\mathrm{CH}$. Consensus review of optimal perioperative care in colorectal surgery: Enhanced Recovery After Surgery (ERAS) Group recommendations. Arch Surg. 2009; 144:961-9.

12. Practice guidelines for obstetric anesthesia: an updated report by the American Society of Anesthesiologists Task Force on Obstetric Anesthesia. Anesthesiology. 2007; 106:843-63. | Article I PubMed

13. Gholitabar M, Ullman R, James D and Griffiths M. Caesarean section: summary of updated NICE guidance. BMJ. 2011; 343:d7108. | Article | PubMed

14. Marom R, Dollberg S, Mimouni FB, Berger I, Mordechayev N, Ochshorn $Y$ and Mandel D. Neonatal blood glucose concentrations in caesarean and vaginally delivered term infants. Acta Paediatr. 2010; 99:1474-7. | Article I PubMed

15. Yamasaki K, Inagaki Y, Mochida S, Funaki K, Takahashi S and Sakamoto S. Effect of intraoperative acetated Ringer's solution with $1 \%$ glucose on glucose and protein metabolism. J Anesth. 2010; 24:426-31. | Article | PubMed

16. Mendiola J, Grylack LJ and Scanlon JW. Effects of intrapartum maternal glucose infusion on the normal fetus and newborn. Anesth Analg. 1982; 61:32-5. | Article | PubMed

17. Cornblath M, Hawdon JM, Williams AF, Aynsley-Green A, Ward-Platt MP, Schwartz R and Kalhan SC. Controversies regarding definition of neonatal hypoglycemia: suggested operational thresholds. Pediatrics. 2000; 105:1141-5. | Article | PubMed

18. Rozance PJ and Hay WW Jr. Describing hypoglycemia-definition or operational threshold? Early Hum Dev. 2010; 86:275-80. | Article

19. Stanley CA, Rozance PJ, Thornton PS, De Leon DD, Harris D, Haymond MW, Hussain K, Levitsky LL, Murad MH, Simmons RA, Sperling MA, Weinstein DA, White NH and Wolfsdorf JI. Re-evaluating "transitional neonatal hypoglycemia": mechanism and implications for management. J Pediatr. 2015; 166:1520-5 e1. | Article | PubMed Abstract | PubMed FullText

20. Alkalay AL, Sarnat HB, Flores-Sarnat L, Elashoff JD, Farber SJ and Simmons CF. Population meta-analysis of low plasma glucose thresholds in full-term normal newborns. Am J Perinatol. 2006; 23:115-9. | Article | PubMed

21. Wight $\mathrm{N}$ and Marinelli KA. ABM clinical protocol \#1: guidelines for blood glucose monitoring and treatment of hypoglycemia in term and 
Yoshizawa et al. Journal of Anesthesiology \& Clinical Science 2018, http://www.hoajonline.com/journals/pdf/2049-9752-7-2.pdf

late-preterm neonates, revised 2014. Breastfeed Med. 2014; 9:173-9. | Article | PubMed Abstract | PubMed FullText

22. Adamkin DH. Postnatal glucose homeostasis in late-preterm and term infants. Pediatrics. 2011; 127:575-9. | Article | PubMed

23. McKinlay CJ, Alsweiler JM, Ansell JM, Anstice NS, Chase JG, Gamble GD, Harris DL, Jacobs RJ, Jiang Y, Paudel N, Signal M, Thompson B, Wouldes TA, Yu TY and Harding JE. Neonatal Glycemia and Neurodevelopmental Outcomes at 2 Years. N Engl J Med. 2015; 373:1507-18. | Article | PubMed Abstract I PubMed FullText

24. Goode RH, Rettiganti M, Li J, Lyle RE, Whiteside-Mansell L, Barrett KW and Casey PH. Developmental Outcomes of Preterm Infants With Neonatal Hypoglycemia. Pediatrics. 2016; 138. | Article I PubMed Abstract | PubMed FullText

25. Kaiser JR, Bai S, Gibson N, Holland G, Lin TM, Swearingen CJ, Mehl JK and ElHassan NO. Association Between Transient Newborn Hypoglycemia and Fourth-Grade Achievement Test Proficiency: A Population-Based Study. JAMA Pediatr. 2015; 169:913-21. | Article | PubMed

\section{Citation:}

Yoshizawa S, Fujita Y, Hoshika M, Kusama N and Sobue K. Effect of maternal low-dose glucose during Cesarean sectionon neonatal hypoglycemia.

J Anesthesiol Clin Sci. 2018; 7:2.

http://dx.doi.org/10.7243/2049-9752-7-2 